\title{
Bilingüismo, individualismo empresarial y el «buen cristiano»: legado misionero entre los urarina de la cuenca del río Chambira (Amazonía peruana)
}

Bilinguisme, individualisme entrepreneurial et le

bon chrétien

: héritage missionnaire parmi les Urarina du bassin de la Chambira (Amazonie péruvienne)

Bilingualism, entrepreneurial individualism and the "good Christian": missionary legacy among the Urarina of the Chambira basin (Peruvian Amazon)

Emanuele Fabiano

\section{Q OpenEdition}

Journals

Edición electrónica

URL: http://journals.openedition.org/bifea/9965

DOI: $10.4000 /$ bifea.9965

ISSN: 2076-5827

Editor

Institut Français d'Études Andines

Edición impresa

Fecha de publicación: 8 diciembre 2018

Paginación: 293-311

ISSN: 0303-7495

Referencia electrónica

Emanuele Fabiano, « Bilingüismo, individualismo empresarial y el «buen cristiano»: legado misionero entre los urarina de la cuenca del río Chambira (Amazonía peruana)», Bulletin de l'Institut français d'études andines [En línea], 47 (3) | 2018, Publicado el 08 diciembre 2018, consultado el 05 noviembre 2020. URL : http://journals.openedition.org/bifea/9965; DOI : https://doi.org/10.4000/bifea.9965

Les contenus du Bulletin de l'Institut français d'études andines sont mis à disposition selon les termes de la licence Creative Commons Attribution - Pas d'Utilisation Commerciale - Pas de Modification 4.0 International. 


\title{
Bilingüismo, individualismo empresarial y el «buen cristiano»: legado misionero entre los urarina de la cuenca del río Chambira (Amazonía peruana)
}

\author{
Emanuele Fabiano*
}

\begin{abstract}
Resumen
El presente artículo analiza la experiencia del pueblo urarina (Amazonía peruana) con los misioneroslingüistas del Instituto Lingüístico de Verano (ILV) para evaluar el valor actual del proceso de la evangelización emprendida a principios de los años 1960. En su intento evangelizador, la labor misionera buscó una mayor participación indígena, alentando una economía de naturaleza empresarial y el surgimiento de Iglesias evangélicas en toda la cuenca del río Chambira. Sin embargo, la recepción por parte de los urarina de los principios que guiaron la acción evangélica marcó el fracaso de las aspiraciones misioneras. Además, dicha experiencia dio lugar a un paradójico efecto de superposición con el modelo de explotación patronal de la «habilitación» que, a lo largo de los años, influyó significativamente sobre la vida económica, política y social indígena. Finalmente, los urarina identifican en la construcción del «buen cristiano» un factor de inestabilidad capaz de afectar a la persona, tanto en su estado físico como en sus funciones de pensamientolmemoria y que, al producir una cercanía al «mundo no indígena» — deseada y en algunos casos económicamente ventajosa—, confiere al mensaje evangélico una ambigüedad inherente, con efectos potencialmente dañinos.
\end{abstract}

Palabras clave: urarina, Amazonía peruana, bilingüismo, misión evangélica, individualismo, economía empresarial

* École des Hautes Études en Sciences Sociales-EHESS - Laboratoire d'Anthropologie Sociale-LAS, 3 rue d'Ulm, 75005 Paris / Pontificia Universidad Católica del Perú-PUCP - Grupo de Antropología Amazónica-GAA: Departamento de Ciencias Sociales, Av. Universitaria 1801, San Miguel -15088, Lima, Perú. E-mail: emanuele.fabiano1@gmail.com 


\title{
Bilinguisme, individualisme entrepreneurial et le "bon chrétien » : héritage missionnaire parmi les Urarina du bassin de la Chambira (Amazonie péruvienne)
}

\section{Résumé}

Cet article analyse l'expérience du peuple Urarina (Amazonie péruvienne) avec les missionnaires linguistes de l'Institut Linguistique d'Été (ILV) afin de faire une évaluation actuelle du processus de l'évangélisation entreprise au début des années 1960. Dans le cadre de leur travail d'évangélisation chez les Urarina, les missionaires visèrent une plus grande participation autochtone en encourageant une économie entrepreneuriale et l'émergence d'Églises évangéliques dans tout le bassin de la Chambira. Cependant, la réception par les indigènes des principes qui ont guidé l'action évangélique a marqué l'échec des aspirations missionnaires. En outre, cette expérience a entraîné un effet paradoxal de chevauchement avec le modèle d'exploitation dit de I'« habilitation » qui, au fil des années, a influencé la vie économique, politique et sociale indigène. Enfin, les Urarina identifient dans la construction du «bon chrétien » un facteur d'instabilité potentielle qui peut porter préjudice à l'individu, aussi bien sur le plan physique qu'au niveau de ses fonctions de penséelmémoire, et donne au message évangélique une ambiguïté inhérente, puisque, en les rapprochant du « monde non indigène » - souhaitée et économiquement avantageuse dans certains cas - elle produit des effets potentiellement nocifs.

Mots-clés : Urarina, Amazonie péruvienne, bilinguisme, mission évangélique, individualisme, économie d'entreprise

\section{Bilingualism, entrepreneurial individualism and the "good Christian": missionary legacy among the Urarina of the Chambira basin (Peruvian Amazon)}

\begin{abstract}
This article aims to analyze the experience of the Urarina of the Peruvian Amazon experience with Summer Institute of Linguistics' (SIL) missionaries and, in particular, the effects today of the evangelization which took place in the beginning of the 1960s. Among the Urarina, the principles of evangelical predication required —among other characteristics - a larger indigenous participation and the encouragement of free market economy. However, this experience was marked by the failure of Urarina's evangelical aspirations. This article also demonstrates how the limited impact of the missionaries' predication provoked a paradoxical overlapping of evangelical principles not so much with "traditional" religious values, but with the system of patronal exploitation known as "habilitación". With the passage of time, this model influenced Urarina's economic, political and social life. Finally, the article focuses on the Urarina perceptions about becoming "good Christians" and how these perceptions — revealing the ambiguity of the evangelical message - are linked to potential instability for both their physical bodies as well as their way of thinking and remembering.
\end{abstract}

Keywords: Urarina, Peruvian Amazonia, bilingualism, evangelical mission, individualism, enterprise economy 


\section{LINGÜISTAS Y MISIONEROS}

La difusión que tuvo el protestantismo durante las últimas décadas, sobre todo en su denominación evangélica y pentecostal, en un medio predominantemente católico, representa un fenómeno a escala global de gran impacto social y cultural (Hefner ed., 1993). En América Latina, el tema destaca a raíz de la rápida difusión de Iglesias protestantes, principalmente en las áreas rurales más pobres y en zonas con un alto porcentaje de población indígena (Freston, 2004: 194). Estas Iglesias proporcionan a sus seguidores indígenas nuevas redes de confraternidad y ayuda mutua basadas en un orden moral y un ethos definido que incitan a sus miembros a buscar una mejora personal. Esto les da oportunidades de adquisición de habilidades organizativas, técnicas y de liderazgo que se suman a una valoración por el ascetismo, en particular por la prohibición del alcohol, y a una ética laboral que promete avances económicos y ascenso social (Martin, 1990).

A pesar de las características recurrentes, numerosos estudios dedicados a la Amazonía indígena han subrayado cómo el cristianismo, en su diversidad de denominaciones, no representa un cuerpo uniforme, sino más bien una multiplicidad de resultados singulares, producida tanto por el encuentro entre distintos colectivos de fieles y sistemas religiosos definidos «tradicionales» como por su propia difusión sociohistórica y por las articulaciones con las realidades indígenas (v. entre otros, Taylor, 1981; Wiik, 2004; Vietta, 2003; Calavia Sáez, 1999; Cabrera, 2013). El esfuerzo intencional y organizado de estos movimientos para controlar a los pueblos indígenas con la introducción de una «nueva religión» se vislumbra a partir de su capacidad de ejecutar estrategias de asistencia y caridad de apropiarse y utilizar elementos culturales locales (sistema de relaciones, organización, lenguaje, producción) en el proceso de evangelización. Esto ha ocasionado la aparición de nuevas formas litúrgicas y expresiones menos rígidas de participación en la vida religiosa que han mitigado el discurso religioso fundamentalista y ascético, poniendo de manifiesto tanto la variabilidad inscrita en estos aparatos ideológicos y religiosos, como su dimensión cultural e incidencia en el cambio social de los grupos involucrados.

En la cuenca del río Chambira, en la Amazonía peruana (departamento de Loreto), los evangélicos constituyen un grupo muy reducido. En los últimos años se ha producido una disminución de la actividad misionera en la región, a pesar de la participación que se registra de los pobladores indígenas urarina en los eventos anuales organizados por distintas Iglesias evangélicas, tanto en la ciudad de Iquitos como en la de Nauta. El número de Iglesias locales activas hoy en día se ha reducido, y entre las más activas se encuentran la comunidad nativa de Nueva Unión así como la de la comunidad nativa de Nuevo Perú, lo que muestra la fase de evidente contracción que el proceso de evangelización está atravesando (fig. 1). Quizás sea debido a las modestas dimensiones de la misión y al enfoque específico en el trabajo de traducción que la influencia evangélica en la cuenca del río Chambira se ha visto muy limitada desde un principio. Por esta razón, hablar de un proceso capilar de conversión urarina resulta injustificado, en cuanto el 


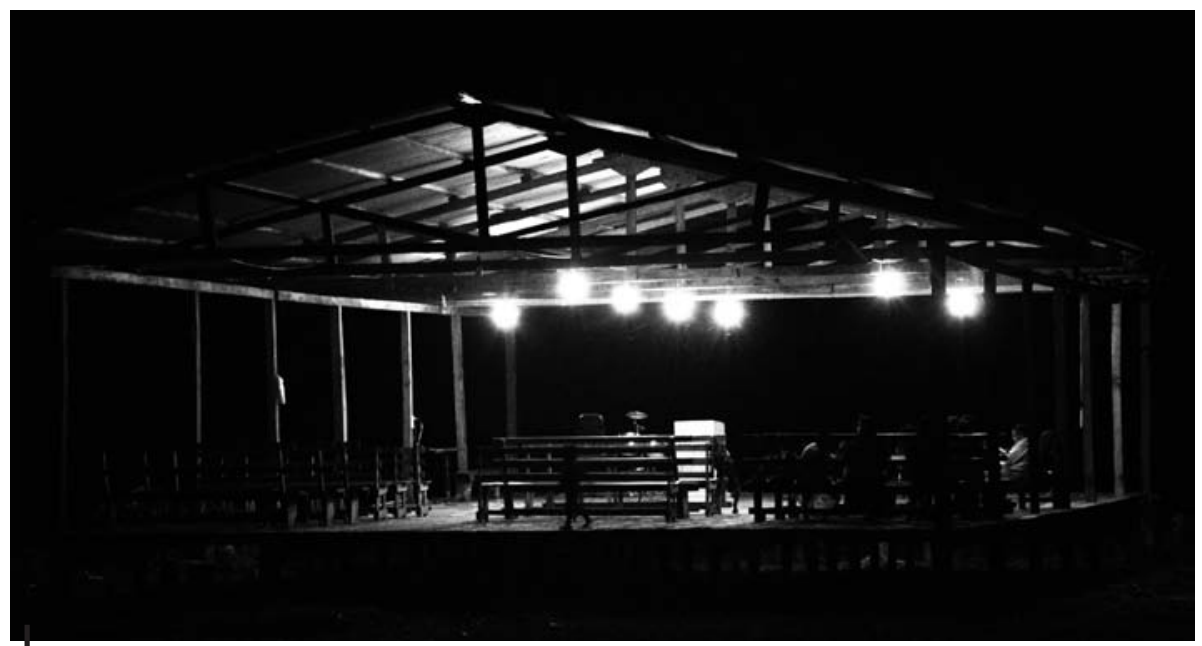

Figura 1 - La nueva iglesia construida en 2016 gracias al apoyo de una congregación evangélica argentina en la comunidad nativa de Nueva Unión (departamento de Loreto)

(C) Emanuele Fabiano, 2017

fenómeno queda caracterizado por su baja intensidad y por los ámbitos reducidos de su alcance. Sin embargo, aunque esté localizado y numéricamente de modesto impacto, su legado conserva todavía cierta relevancia en la vida política y social de las comunidades urarinas, de aquellas comunidades urarinas que en el pasado estuvieron mayormente involucradas con los misioneros-lingüistas del ILV.

El Instituto Lingüístico de Verano (ILV) emprendió de modo estable sus actividades en la región en 1960, año que coincidió con la llegada a la quebrada Tigrillo de la primera pareja de lingüistas afiliados a la organización. En aquel entonces, toda la zona estaba siendo explotada por la familia Ocampo de Iquitos, cuyos miembros fueron los primeros en recibir a los misioneros estadounidenses proporcionándoles apoyo material y logístico para que pudieran establecerse de forma permanente. Como bien lo explica B. Dean $(2009 ;$ 1999), la presencia de los patrones en esta primera fase resulta funcional al ingreso de otros actores en la región, de momento que la forma de patronazgo ejercida en la cuenca del Chambira ha estructurado relaciones asimétricas capaces de vincular la población indígena local a través de lazos verticales de interdependencia mutua según el modelo de «patrón-cliente». Esto explicaría, por lo tanto, cómo la figura del mpatrón\} desempeñaría el rol de intermediario entre los grupos urarina y la sociedad nacional, siendo al mismo tiempo un aliado comercial pero también el responsable de actos de intimidación y subyugación social (Walker, 2013; 2012).

Durante todo el periodo de actividad de la misión, el trabajo de evangelización se articuló a través de distintas actividades organizadas y secuenciadas a partir de dos ejes principales: en primer lugar, la educación bilingüe y, sucesivamente, la organización de empresas comunales. En coherencia con el fin de favorecer una inserción gradual, necesaria para emprender las actividades de traducción, 
en primera instancia se procedió a la alfabetización de un grupo de pobladores urarina; luego, hubo una selección y sucesiva formación de traductores para la realización de una edición del Nuevo Testamento en lengua indígena. Entre las distintas herramientas empleadas para la evangelización, la definida como traslation strategy (Rafael, 2015; D'Angelis, 2004) fue sin duda la que tuvo el mayor impacto entre los urarina. Esta emplea la lengua indígena, o heart language (Handman, 2007) para dar paso a las primeras labores de evangelización a través de la traducción, sin que para ello sea necesaria la organización de una comunidad inicial de fieles o de una Iglesia ya establecida (fig. 2). De esta forma, es posible configurar de manera diferencial patrones de evangelización específicos que son elaborados prescindiendo de una rígida orientación denominacional o de una larga formación doctrinal (Dye, 1979: 17). El objetivo resulta muy pragmático: formar una cierta cantidad de traductores y, a raíz de esto, constituir un pequeño grupo de trabajo que, mediante el contacto directo y la interacción constante, pueda ser evangelizado y sucesivamente empleado para implantar los cimientos de una Iglesia local. Asimismo, el trabajo compartido con el misionero-lingüista fortalece también la relación entre la población y la misión (Barros, 2004: 47), lo cual asegura el beneficioso desarrollo de otras actividades y un mayor nivel de control.

Como se evidencia también en el caso urarina, solo después de haber impulsado programas para la educación bilingüe, resulta viable fomentar el surgimiento de pequeñas empresas comunales, cuya función es sustentar las nuevas Iglesias y las sucesivas actividades de la misión más allá del área de actividad, expandiendo

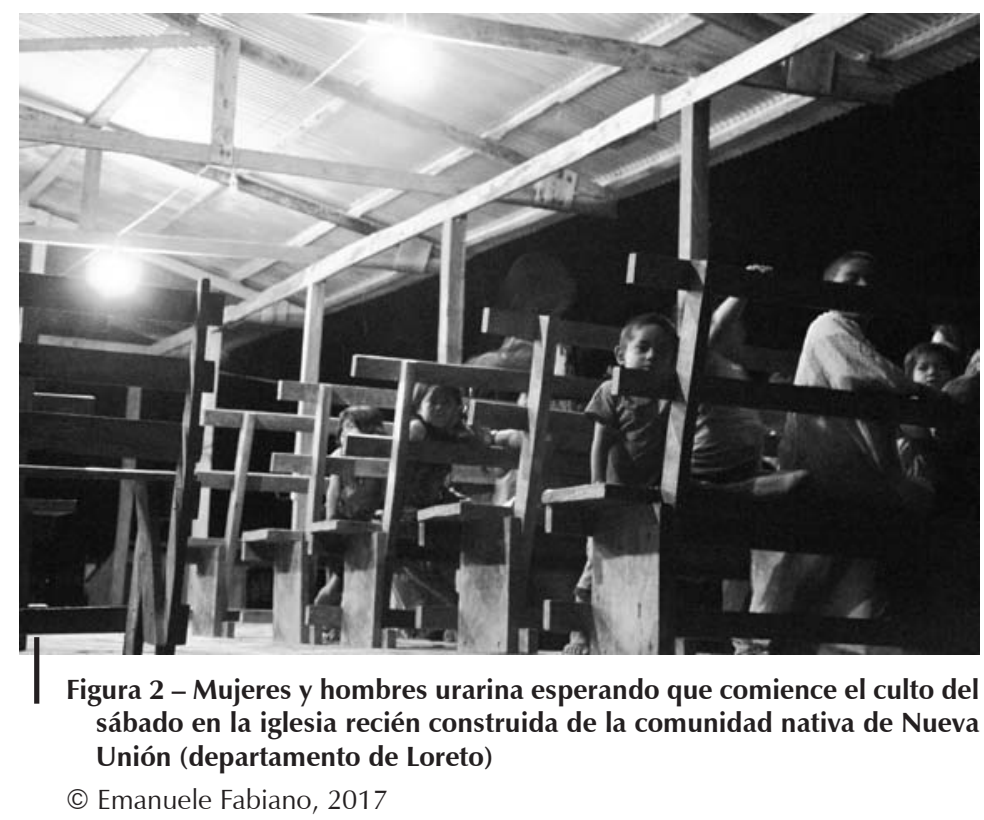


de esta forma su influencia en toda la región. Dicho propósito aclara también el intento por parte de los misioneros, por desvincular del sistema económico de la «habilitación» a las familias urarina más cercanas a la misión (Walker, 2012). Esto se debe a que este mecanismo de explotación, a pesar de alimentar formas de trabajo con rasgos marcadamente individualistas, no permitía la creación de un sujeto social indígena económicamente autónomo en consonancia con los principios protestantes.

El objetivo final para ambos ejes de trabajo —la traducción y la creación de empresas urarina- fue el de favorecer el proceso de evangelización mediante una dinámica de «filtración». De manera concreta, esto significa emplear inicialmente como agentes in loco a los mismos traductores indígenas, y solo en una segunda etapa a los profesores bilingües, ya que estos se convertirían en los vectores del mensaje evangélico en la comunidad de procedencia, o en su propia sede de trabajo, y al mismo tiempo en el órgano administrativo para una economía a escala comunal. No es de sorprender, entonces, como ocurre hasta el día de hoy, que muchos de mis interlocutores, al recordar las primeras relaciones con la pareja de misioneros, subrayen de forma casi caricatural su interés obsesivo por la lengua urarina y por la traducción de la Biblia. Esta impresión sigue siendo tan arraigada hoy en día que un hombre de 65 años, aún joven cuando se estableció la misión, comenta de este modo las actividades de los misioneros:

Los patrones trabajaban madera, trabajaban arroz y ganado. Trabajaban todo esto y lo envían a Iquitos. Pero los gringos que estaban con ellos no, ellos trabajaban en biblias y como por la madera. Todo esto se llevaba a Iquitos, porque ellos decían que después las biblias iban a volver al Chambira. Y la gente se preguntaba cómo alguien se puede desesperar por esto y si era cierto que con la biblia se podría sacar plata, como con la madera.

\section{HERRAMIENTAS DE CONVERSIÓN Y LEGADO MISIONERO EN LA CUENCA DEL CHAMBIRA}

No obstante la importancia otorgada a las labores de traducción, esto no ha sido el único proyecto desarrollado entre los urarina por los misioneros del ILV; aun así, este fue el que, sin duda, tuvo mayor éxito por sus resultados más notables a largo plazo. Queda claro, entonces cómo, en razón de este mismo objetivo, la educación formal bilingüe ha gozado de una dedicación constante y, en el marco de los proyectos misioneros, representó siempre una premisa necesaria para individuar y formar potenciales traductores o establecer alianzas. A pesar de su relevancia, después del entusiasmo inicial - aunque modesto- muy pronto el sistema a través del cual la educación formal era impartida en la escuela de la misión presentó sus primeras deficiencias. En particular, se menciona la dificultad de cumplir con la demanda de asistencia que se les exigía a los estudiantes, en su mayoría hombres adultos, sin que eso perjudicara su desempeño en el trabajo. Muchos urarina, al parecer, vieron en las clases viendo en estas una oportunidad 
de trabajar en condiciones menos duras y sacrificadas que con los patrones y sus capataces. La posibilidad de recibir algún beneficio o, en todo caso, de mantener vigentes los acuerdos estipulados con los patrones a cambio de un esfuerzo menor, fue una de las razones que, en un primer momento, facilitó el programa de la pareja de misioneros-lingüistas. Desde luego, estas expectativas fueron desatendidas, debido a que la misión promovía el acceso voluntario a la formación escolar con base en un principio de autoprogreso personal, desvinculándolo de la relación laboral y sobre todo rehusándose a cualquier tipo de retribución.

Si el intento de impulsar una instrucción formal orientada a la traducción presentó una serie de obstáculos, es sobre todo durante la implementación de actividades empresariales locales, destinadas a disminuir el control patronal sobre los urarina, que se registraron las mayores dificultades. Por ejemplo, la misión proporcionaba todo el apoyo logístico y legal para la titulación de las comunidades indígenas y la demarcación del territorio comunal, con el fin de incentivar la explotación de los recursos maderables por parte de los urarina sin la mediación de los patrones. Otra actividad fuertemente impulsada por los misioneros fue la preparación de pastizales para la crianza de ganado en un fundo ubicado cerca de la ciudad de Nauta. En todos estos casos, los resultados fueron muy modestos, marcando el fracaso de las aspiraciones de los misioneros con miras a una planificación económica local a largo plazo. Al mismo tiempo, esto reveló también las dificultades de incluir de forma sistemática a un mayor número de pobladores urarina en estas actividades, lo cual, además, impidió la formación de nuevas Iglesias y favoreció contextualmente la dispersión de los pocos adultos que ya habían recibido una primera y básica educación formal bilingüe. Por varios años esto no permitió poner en marcha el proyecto de capacitación a largo plazo de los traductores y fortaleció aún más la relación de dependencia con los misioneros.

Estas dificultades fueron compensadas parcialmente activando programas asistencialistas dirigidos de manera específica a las familias más involucradas con el fin de acercarlas todavía más a la misión; objetivo que se logró sobre todo con los integrantes del primer grupo de traductores urarina. Además de pequeños montos de dinero y productos, se garantizaba tanto para los hijos de los miembros del pequeño grupo de feligreses como para los de los traductores el acceso a una instrucción formal de nivel primario, y después a un Centro de Educación Básica Alternativa (CEBA) de nivel secundario, manejado en la ciudad de Iquitos por una congregación evangélica cercana al ILV. De esta forma, no solamente se insertó el trabajo de traducción dentro de una relación de reciprocidad que enganchaba a los traductores, asegurando así la continuidad de las actividades, sino también se establecieron las bases para la actual Asociación de Maestros Bilingües Urarina del Río Chambira (AMABIURCHA), también conocida simplemente como «Red», y para la creación de un nuevo sujeto político representado por la figura del profesor indígena.

En pocos años, convertirse en un profesor bilingüe se volvió una aspiración personal y familiar, en cuanto permitía a muchos jóvenes adquirir una mayor independencia económica, además de nuevas capacidades para relacionarse con la sociedad no indígena y las instituciones del Estado. El dominio del español, tanto oral como 
escrito, se volvió un instrumento valioso a la hora de desempeñarse en un contexto cada día más expuesto a la sociedad nacional a tal punto que el desarrollo de un adecuado bilingüismo funcional, junto con el aprendizaje de ciertas habilidades burocráticas, es considerado fundamental. Por lo tanto, se podría afirmar que la centralidad del trabajo de traducción y la enseñanza bilingüe representan el legado más persistente de la experiencia misionera, a tal punto que sigue caracterizando el discurso evangélico en la región.

\section{3. «BUEN PATRÓN» Y «PATRÓN MALO»}

Al promover una nueva moral y un código ético cristiano mediante herramientas como la traducción y un asistencialismo de rasgos paternalistas, las estrategias de evangelización apenas lograron una inserción superficial en el aparato ideológico y cosmológico urarina. Por el contrario, las medidas empleadas para favorecer la filtración de la religión en el tejido social local tuvieron un inesperado efecto de superposición entre la arraigada experiencia social urarina de subordinación al régimen patronal y las ambiciones evangélicas de desarrollo personal e independencia económica. De forma paradójica, a pesar de los esfuerzos invertidos por los misioneros, el discurso urarina nunca reconoció en las enseñanzas evangélicas la autoridad para actuar en favor de una mayor autonomía económica o para rechazar las prácticas de subyugación patronales, y lo inscribió más bien dentro de un ethos referente a una nueva categoría de patrón, identificada como «buen patrón»:

Ellos [la pareja de misioneros] vivían cerca de los patrones, él con su mujer vivía. El patrón nos dijo que teníamos que ayudarle y que él [el misionero] nos iba a tratar bien, como cualquier otro patrón cuando uno trabaja. Dijeron que teníamos que escucharlo. Así que mucha gente empezó a hablar, a decir que el gringo los trataba bien, que a veces le regalaba cosas, que les explicaba de la Biblia. Decían que era como el patrón, él también tenía ganado, tenía su avioneta y su casa en lquitos. Pero era mejor que el patrón, era nuevo, era «buen patrón». Así decían algunos.

En un principio, esta superposición entre patrones y misioneros motivó que un discreto número de urarina se acercara a los lingüistas extranjeros. Estos, en razón de un aparente distanciamiento Poco contentos del sistema de «habilitación» vigente en ese entonces, los urarina buscaban en ellos los representantes de una forma alternativa de patronazgo; para ser más precisos, una versión «buena» y menos violenta. La presencia de otros «blancos» o mestizos no religiosos en comunidades indígenas no generó un problema para la «misión de fe» ni redujo sus posibilidades de acción; por el contrario, esto parece haber reforzado el rol del misionero al reubicarlo dentro de una estructura social ya establecida y perfectamente inteligible. Se podría hallar una posible explicación de ello en la presencia de algunos atributos distintivos que permitirían vincular la misión y sus representantes con la figura «clásica» del patrón, entre los cuales destacarían como características el no ser indígena, el marcado paternalismo y la valoración por una forma de trabajo de rasgo individualista (Córdoba, 2012). 
En su estudio clásico sobre el evangelismo en comunidades rurales, Lalive D’Epinay (1975) señala como uno de sus rasgos distintivos la predisposición hacia la reproducción de la estructura patronal tradicional de la hacienda y la promoción entre los feligreses de actitudes conservadoras y pasivas ante la autoridad. Por lo tanto, según este autor, una característica importante de este tipo de religiosidad es la de ser un desactivador de la acción política y, al mismo tiempo, un inhibidor de la movilidad social. Esto ocurriría a partir del sustancial abandono de los sistemas tradicionales familiares y paternalistas que caracterizaban las grandes haciendas, junto con la necesidad de llenar este vacío ofreciendo al individuo integrarse a un grupo, a la comunidad religiosa, cuya forma de organización reproduce en buena medida el modelo anterior. Lo que ocurre en este caso es entonces una «substitución» dentro de un marco ideológico de matriz cristiana capaz de mantener inalteradas las lógicas de subyugación y dependencia. Dicho dispositivo induciría un proceso de enajenamiento de la sociedad en el cual estarían involucrados no solamente la comunidad religiosa en tanto institución formalizada, sino también sus miembros (Lalive D'Epinay, 1975: 165).

Según esta lectura, el rasgo político distintivo del evangelismo resulta ser la pasividad que se traduce en el mandamiento de la sumisión a las autoridades a través de la recuperación de estructuras sociopolíticas patronales (Lalive D’Epinay, 1975: 180). A pesar de que el fenómeno de sustitución teorizado por Lalive D’Epinay resulte muy sugerente, su análisis acerca de los efectos pasivizantes de este proceso se revela inadecuado para dar cuenta de los efectos a largo plazo entre los urarina. Dicho de otro modo, aunque la aparición de un protestantismo urarina no contribuyó a conformar una conducta social favorable a la actividad económica y a la innovación, no dio lugar a una desactivación en el ámbito social y político, sino más bien representó un poderoso agente transformador. En este sentido, una de las primeras responsabilidades que se le reconoce al mensaje evangélico llevado por los misioneros-lingüistas del ILV es de haber promovido, por un lado, la sustancial disolución de los vínculos de solidaridad vigentes entre los trabajadores habilitados y, por el otro, la introducción de privilegios, tanto en términos económicos como en el acceso a los servicios de educación y salud ofrecidos por la ciudad. G., un hombre originario del río Tigrillo, quien en el pasado se opuso a la presencia evangélica en la región, argumenta de la siguiente forma las razones de su aversión:

Mientras que el alcohol nos hacía todos iguales, todos pobres iguales y todos bajo el mando del patrón y sus capataces, los gringos han hecho a algunos más ricos y a otros los han dejado pobres. Unos poquitos que están con los gringos y son «hermanos», y después hay otros que están solo con su gente [los urarina]. Es como si [los misioneros] intentaron hacer pequeños patrones entre los urarina. Pero eso no puede pasar.

Se agudizó entre los urarina la percepción de que una mayor participación en el medio social evangélico implicaría también una mayor cercanía a los «blancos» y mestizos, acareando consigo consecuencias dañinas. Esto se debe sobre todo a la influencia ejercida por los misioneros extranjeros — los «patrones buenos»— y 
su sistema de valores, más que a la dimensión doctrinaria y religiosa. En este sentido, como afirman los no evangélicos, la relación con los misioneros, y no la asidua participación a las actividades de una determinada Iglesia o un genérico interés por las enseñanzas cristianas, constituye una de las razones principales de la difusión de una actitud antisocial que, al «favorecer a unos pocos, sacrificando a los demás», transforma a los urarina en «pequeños patrones». Esta convicción justificaría la oposición que muchos manifiestan hacia el cristianismo, y por lo tanto, hacia los proyectos de los misioneros «buenos patrones», en cuanto representantes de esta misma ideología. Como lo relata R., un hombre de 53 años:

Cuando han venido estos gringos, estos «hermanos», para hacer las traducciones, se han acercado a la gente que podía ayudarle. Le han dicho al patrón lo que querían hacer y él le ha dicho que sí, que podían. La gente que estaba con ellos recibía ropa, cosas, pero sin trabajar, así que más gente quería estar con ellos. Pero los gringos le dijeron que no. La gente no entendía cómo era posible tener cosas sin trabajar, solo con hacer traducciones de algo, hablando. Los gringos decían que ellos podían enseñarnos a nosotros también, que ellos eran urarina como nosotros, pero sabían más, podían hacer los papeles en la ciudad y decidir cosas para la comunidad porque estudiaban. Pero ahora nosotros también ya sabemos estas cosas [...] Así que eligieron gente para trabajar, y le daban cosas, incluso medicamentos, mientras que a los demás no les daban nada. No eran ricos como ellos [los misioneros] pero ya no eran tan pobres como cuando trabajaban con el patrón. Algo habían ganado también, y sin levantar machete. Ahora sí tenían cosas, más que antes, y se sentían mejor que los demás.

\section{RECIBIR LA PALABRA}

Debido a las características conflictivas y antisociales que se le reconocen a la proximidad con las Iglesias evangélicas y sus representantes, para muchos urarina la adhesión al evangelismo se justificaría solo en función de los beneficios económicos o materiales obtenidos como contraparte de la filiación religiosa. Aunque los creyentes recusen esta explicación economicista, anteponiéndole más bien una genérica idea de «progreso personal», la inicial participación al proyecto misionero a través de la relación directa con la pareja norteamericana ha representado, sin duda, un medio de acceso a modestos beneficios y bienes de consumo que anteriormente eran prerrogativa exclusiva de los patrones.

La asimilación de estos aspectos asociados al mensaje y a la práctica cristiana, junto con la preservación de algunos de los rasgos distintivos inherentes al sistema económico patronal preexistente, se tradujo en un sentimiento generalizado de desconfianza hacia la presencia evangélica y sus estrategias de evangelización. Aunque esta explicación no encuentre una adhesión unánime, resulta útil para aclarar qué argumentos avalan las explícitas manifestaciones de disidencia, e incluso de rechazo, hacia el discurso y las enseñanzas evangélicos. Sin la 
pretensión de ser exhaustivo, se podría afirmar que la crítica hacia el evangelismo entre los urarina se desarrolla siguiendo una doble vertiente argumentativa: por un lado existe un rechazo hacia cierta idea de individualismo, percibido como fundamento ideológico del proyecto misionero; por el otro, se manifiesta un temor hacia las posibles consecuencias de un mayor involucramiento con los misioneros extranjeros, entendido en su dimensión simbólica pero sobre todo física y material (Opas, 2014).

Desde el punto de vista ideológico, para los urarina, el evangelismo alienta a sus seguidores a tomar el poder sobre sus vidas; un mayor control que pueda simultáneamente infundir en ellos la esperanza de una mejora a través de la consecución de nuevos bienes y a la vez favorecer la adquisición de conocimientos procedentes de entidades espirituales, en muchos casos dañinas, arraigadas profundamente en culturas foráneas. Los riesgos asociados a la conversión pueden ser ilustrados también a partir de la naturaleza misma del contacto con los promotores extranjeros y la posesión de sus objetos. Un ejemplo paradigmático está representado por las propiedades intrínsecas que muchos urarina reconocen en la biblia en cuanto «tecnología religiosa» foránea. Esto demuestra tener cierta relación con la relevancia que, a lo largo de todo el proyecto de evangelización, se le ha otorgado a la traducción. Esto, no sin ambigüedades, encuentra el aprecio

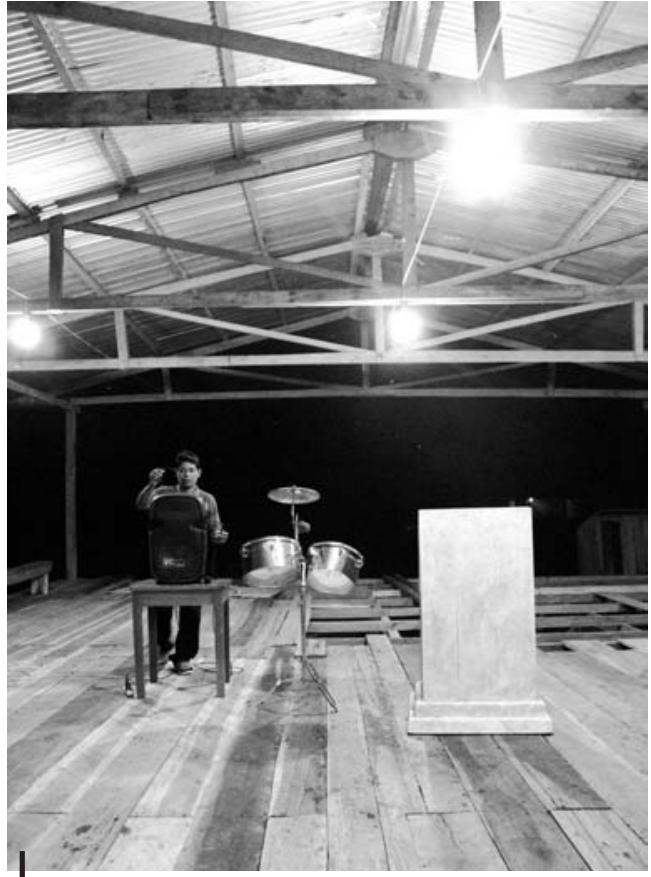

Figura 3 - Un poblador urarina prepara el parlante, alimentado por un generador de luz, antes de empezar el culto en la comunidad nativa de Nueva Unión (departamento de Loreto)

(C) Emanuele Fabiano, 2017 de muchos urarina, ya que las competencias en el uso de la lengua escrita y el bilingüismo facilitan el acceso al universo socioeconómico mestizo. Además, revela cómo dentro de la lógica urarina tanto la retórica evangélica como el «intercambio de palabras» están asociados al pago individual por los servicios prestados en la traducción y sus posibilidades en términos económicos y en la adquisición de prestigio (fig. 3).

Una de las características que mejor distingue a los evangélicos es su literalismo a la hora de aproximarse al texto bíblico y de interpretarlo; en este sentido, el enfoque urarina posee significativas diferencias. En lugar de interpretar la Biblia apelando a una traducción denominacional como parte de un corpus evangélico específico, la interpretación urarina del texto bíblico, y en particular del Nuevo Testamento, se ha enriquecido a lo largo de los años con conceptos referentes a elementos cosmológicos locales provenientes de una retórica que reivindica una superioridad moral urarina sobre la decadencia de la sociedad mestiza. Tal interpretación enfatiza que solo las enseñanzas pragmáticas se obtienen del mensaje evangélico en consonancia con la aspiración urarina de pertenecer a una «lglesia», 
esta entendida no solamente como conjunto de personas que profesan la misma fe, sino también como comunidad autónoma que establece de por sí normas y valores útiles a la convivencia y al acceso al medio social no indígena, a sus bienes y servicios.

Además, paralelamente a su valor gnoseológico, se otorga también a las enseñanzas bíblicas — parábolas, proverbios y discursos alegóricos - una función específica en la construcción de un «buen cristiano» que se da a través de la concreta incorporación de una dotación de nuevos conocimientos (Opas, 2016; 2006). En una ocasión, por ejemplo, un feligrés urarina explicó que tras haber escuchado por varias noches seguidas las palabras grabadas en un aparato de reproducción solar, estas se habían insertado dentro de él, e incluso sin entender por completo el significado, su corazón había mutado al igual que su sangre. Otro hombre estaba persuadido de que, a pesar de su analfabetismo, la copia en lengua castellana de la biblia que, meses antes, le había regalado un misionero, le estaba «aconsejando» mejor que la versión en lengua urarina. Su convicción se sustentaba en la idea de que la cercanía con el libro favorecía el acceso a todo un aparato de conocimientos útiles para superar las pruebas impuestas por Dios y que, al igual que los misioneros, esto le permitía convertirse en un verdadero cristiano.

Mis interlocutores urarina reconocen, pues, una dimensión material a la Biblia y, en general, al discurso evangélico que, bajo ciertas condiciones, tiene la capacidad de transmitir conocimiento e inducir un cambio en su posesor. No debe sorprender entonces que, a pesar de los riesgos que los urarina no evangélicos reconocen en estos instrumentos, incluso los que frecuentan solo ocasionalmente una iglesia o demuestran tener una posición crítica hacia sus instituciones, poseen una copia de la biblia que, en la mayor parte de los casos, se cuida con mucha atención, envolviéndola en plástico y guardándola entre las cosas más preciadas de la casa. Poseer varias copias y a veces en distintas lenguas — urarina, castellano o inglésindica por lo tanto el grado de compromiso con el mensaje evangélico. Como lo explica G.:

Conocer las palabras de la Biblia es bueno para un pastor o una persona que se dedica a esto. Las palabras debes estar en él para que pueda servir de algo. A veces las dicen... a veces la conocen en otra lengua [castellano], porque hay cosas que solo pueden decirse en castellano y otras en urarina. Y esto es cierto, incluso cuando uno le pide algo a Dios. Si lo hace de otra forma él [dios] no entiende. No es urarina, y por eso habla otra lengua que una persona debe conocer.

Conservar las «palabras», entenderlas y compartirlas es el primer paso para la «Conversión». Esto, según los no evangélicos, guardaría en sí un poder dañino, en cuanto la peligrosidad vinculada al cristianismo se asocia de forma directa a la posesión y, sobre todo, del aprendizaje mnemónico del texto bíblico. Una parte del vocabulario referente a la conversión refleja esta convicción y enfatiza de forma evidente las implicaciones físicas y materiales del discurso religioso y, en general, el uso de palabras (cfr. Fabiano, 2015a). Este aspecto trasluce, por ejemplo, en el uso de la expresión esenetia, en el sentido de «rechazo» o «no creer», cuyo 
significado literal es «dejar algo sin recoger», y explica cómo las manifestaciones de repulsa hacia el evangelismo por parte de los urarina no evangélicos se sustentarían precisamente en la falta de confianza hacia algo que se piensa dañino o falso. A la inversa, el verbo jeriia es usado con frecuencia en el sentido de «acoger», «aceptar», y su significado común es el de «creer». Por lo tanto, el creyente es a la vez aquel que «cree» en las enseñanzas bíblicas y alguien que se compromete materialmente en cuidarlas, y las hace suyas a través de la posesión, o sea que las «recoge» y las «pone» en sí mismo.

La idea de una evangelización a través de una incorporación material del mensaje cristiano parece ser un tema central del proceso de conversión también entre otros pueblos indígenas amazónicos. Como lo señala C. Howard, por ejemplo, los waiwai convertidos afirman la necesidad de aceptar a Jesús dentro de su propio vientre, identificable como el centro de las emociones, para que este pueda atarse al alma o espíritu de la persona receptora, la cual obtendrá así la salvación y finalmente la vida eterna (Howard, 2001: 342). Por lo contrario, esto no parece ser el caso de los urarina cuyo propósito no es tanto incorporar la divinidad, sino más bien adquirir un repertorio de enseñanzas que ofrezcan una protección, gracias a nuevos poderes espirituales y un mayor nivel de entendimiento sobre la realidad no indígena. Bajo esta perspectiva poseer una biblia, al igual que cualquier otro artefacto llevado por los misioneros para facilitar la evangelización, como reproductores audio y linternas solares, colecciones de sermones en mp3 o medicamentos producidos en los Estados Unidos, indica cierta familiaridad con el mensaje cristiano y los emisarios extranjeros. Así mismo, su posesión implica la adquisición de conocimientos cuyos beneficios se miden a través de una mayor legitimación social entre los mestizos, o en la posibilidad de pertenecer a una extensa comunidad de fieles y sus beneficios implícitos.

No debe sorprender entonces cómo, en algunos casos, la decisión de volverse «hermano» o «hermana» es considerada un alejamiento de la esfera social urarina, revelado por un injustificado deseo de objetos, dinero y reconocimiento personal. La explicación se da a partir de un marco interpretativo chamánico que reconoce en ello un agente etiológico capaz de producir una degeneración o un cambio orgánico de la sangre y todas las actividades de pensamientol memoria (cf. Belaunde, 2006: 206-207; Fabiano, 2015a; 2015b) asociado a las enfermedades pertenecientes a la categoría janai. Por lo que concierne a este tipo de enfermedades, el daño hacia el cuerpo se debe a la introducción de dardos patógenos (batui), cuyo objetivo es comprometer las defensas mediante un elemento nocivo que penetra a través de la piel, para luego adquirir la capacidad de desplazarse usando el torrente sanguíneo, hasta llegar a enfermar el corazón (kuri) y el líquido encargado de todas las actividades de pensamiento (akarera) (Fabiano, 2015a; 2015b). Estas afecciones encuentran su propio origen en la voluntad maligna de un agente patógeno no humano, a diferencia de los ataques de brujería (satiia) causados por voluntad de un humano. En la categoría de janai se encuentra una gran variedad de enfermedades cuyos responsables son los espíritus de animales depredadores, de elementos del paisaje o de algunos vegetales, que se identifican con el nombre genérico de nijniaeene (Elkins, 1993). 
Según esta misma lógica, volverse evangélico es la consecuencia directa de la introducción de sustancias dañinas, facilitada por la cercanía física o por estrechar manos en la conclusión de una tarde en la iglesia, mediante la ingestión de comida ofrecida durante las reuniones en Iquitos o los eventos anuales organizados en las comunidades ribereñas, pero también recibiendo los regalos procedentes del extranjero, como ropa o medicamentos con nombres e indicaciones en inglés.

Además de las consecuencias dañinas relativas al uso y posesión de las tecnologías religiosas y del efecto potencialmente patógeno de las palabras bíblicas, se atribuye a los evangélicos de manera general una relación exclusiva con el Dios cristiano. Al igual que otras categorías de espíritus asociados a enfermedades contagiosas, a la brujería o a las actividades extractivas, esta entidad no humana tiene en mayor o menor medida cierto grado de similitud con los misioneros extranjeros y la sociedad no indígena; las características que se les atribuyen revierten tanto en el modo de ser como en las actitudes sociales reconocidas a los fieles (fig. 4). En definitiva, como la cercanía con los misioneros determina un acceso a beneficios y reconocimiento, es sobre todo en relación a los conocimientos procedentes del Dios cristiano que, según sus detractores, el evangelismo resultaría contraproducente en sus pretensiones salvadoras y socavaría cualquier esfuerzo para conseguir una vida sana. En particular, la caracterización del Dios cristiano y su hijo Jesúcristo alimenta una animada confrontación entre evangélicos y no evangélicos. Para los no evangélicos, la figura del Dios cristiano sería, en realidad, aunque bajo otro nombre, el equivalente del diablo urarina (mokonajaera), es decir, el «dios de los mestizos», y por lo tanto su hijo Jesúcristo (Jesusu Keresto) el «hijo del diablo» (Walker, 2012).

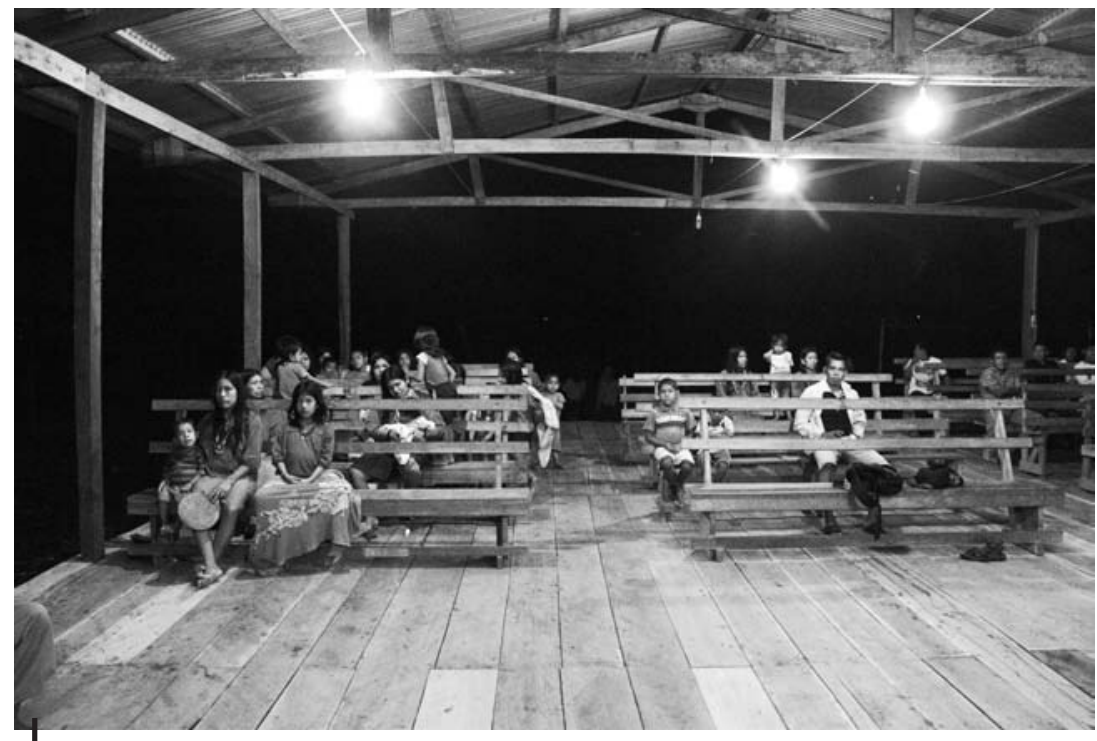

Figura 4 - Iglesia evangélica de la comunidad nativa de Nueva Unión (departamento de Loreto) 
En esta disputa teológica que opone el «Dios de los blancos» al «Dios de los urarina» se incorporan también algunos de los rasgos distintivos de las difíciles relaciones interétnicas con la sociedad mestiza. Por un lado, se encuentra Kana Kuaünera, «Nuestro Creador», antiguo demiurgo habitante del «Mundo del Cielo» (Kuanra Nenaja), y sus hijos los Arara, entre los cuales se encuentra Surestu, «el enviado a la tierra de Kana Kuaaünera»; por el otro, el Dios cristiano y su hijo que, como me dijo un joven urarina «[...], junto al diablo viven en el cielo, hablan la misma lengua [de los mestizos], y piensan solo en negocios y dinero[...]». Para los fieles urarina, quienes niegan obviamente esta interpretación, esta sería el resultado del desconocimiento de la Biblia y del analfabetismo, y se trataría de una simple equivocación debido a una traducción incorrecta o a un común malentendido. A pesar de las ambigüedades terminológicas, la coincidencia entre el Diablo y el Dios cristiano es la demostración de cómo, según algunos, con frecuencia, la religión evangélica y el progreso económico van juntos, y cuando esto ocurre, parecen apoyarse y reforzarse mutuamente el uno al otro en detrimento de la colectividad. Secundando esta interpretación, entonces, el «Dios de los blancos», Mukunajaera, apoyaría a sus fieles para que se conviertan en comerciantes, alimentando codicia, desconfianza y pobreza entre los urarina (Walker, 2012).

Según mis interlocutores, cada una de estas actitudes caracterizaría también el individualismo empresarial que está a la base de cualquier forma de explotación y de los negocios fraudulentos, prácticas que agentes foráneos promueven mediante la introducción de formas coercitivas de control, como la inscripción en el registro civil, el documento de identidad, la burocracia y las tarjetas de crédito (Allard, 2012; Walker, 2016). Por esta razón, no pasa desapercibida la analogía entre la aparición invasiva de un nijniaeene, interpretable como la expresión de cierta irregularidad del orden del mundo, y los riesgos implicados en una mayor cercanía a blancos y mestizos o la conversión al evangelismo. En ambos casos, se trata de una intrusión en el dominio de la sociabilidad urarina que, si no se gestiona oportunamente, puede tener efectos negativos tanto para la persona como para la comunidad en general.

\section{CONCLUSIONES}

El análisis de los elementos que han caracterizado la evangelización urarina permite evaluar los efectos a largo plazo de estos procesos en el contexto indígena contemporáneo. Aunque con frecuencia para el protestantismo indígena, al igual que para las otras «versiones mestizas», el contexto inicial de la inserción suele ser el colapso de las antiguas formas de organización social entre los urarina, ésta ha agudizado las divisiones que ya existían y creado nuevas. La presencia misionera en la región ha favorecido la reconstrucción de relaciones a escala local según configuraciones dotadas de morfologías distintas a las anteriores, moldeadas por tramas ideológicas y sociológicas de matriz cristiana, pero sin llevar al abandono de las formas anteriores. Como lo indica Robbins (2004) la 
introducción de un implante ideológico cristiano en contextos indígenas puede ocasionar la convivencia de dos sistemas de valores diferentes que se produce en el momento en que se verifica la adopción de un modelo cultural inédito. En este caso, lo que ocurre no es simplemente la asimilación de nuevas normas y reglas de conducta o nuevos valores para la cultura receptora; tampoco se trata de una trasformación estructural que consentiría preservar el sistema «original». Más bien sería una superposición de sistemas distintos que, por lo tanto, seguirían contemporáneamente activos.

Bajo esta misma lógica, el tipo de cristianismo adoptado por los urarina no establece una tensión irreconciliable entre una estricta moral cristiana, que aseguraría la salvación individual a través de la observancia de los preceptos evangélicos, y un ámbito mundano asociado a un modo de vida «precristiano» o indígena; más bien, sigue manteniendo intacta la percepción de ambigüedad inherente al mensaje evangélico y a sus representantes. Sin duda, el discurso urarina sigue asociando la cercanía al evangelismo con una mayor movilidad relativa en términos sociales y económicos. Esto supone actitudes mezquinas, avidez y el deseo injustificado por la acumulación innecesaria de objetos que representan claros indicadores de un radical alejamiento de los valores urarina y de una mayor proximidad al universo social no indígena, de los patrones y misioneros extranjeros (cf. también Walker, 2013). En este sentido, la fe evangélica y la cercanía al Dios cristiano que alimentan la propensión a la búsqueda de riqueza y deseos de prosperidad material, no se interpretan como una bendición divina o el signo de un ascenso social y económico, sino como el resultado de un desequilibrio activado por un proceso de desestabilización social, lo cual explica cómo la conversión o la simple filiación religiosa puede volverse el catalizador de un proceso que conlleva una inestabilidad radical, tanto física como social (Vilaça, 2015).

Sin embargo, la incorporación del mensaje evangélico es coherente con la valoración urarina de la adquisición de conocimientos procedentes de un medio no indígena y desvela tanto los límites como las potencialidades de una ideología orientada hacia el desarrollo de una conciencia individualista y empresarial, percibida como una herramienta de inclusión en la sociedad nacional. El evangelismo urarina con su rechazo hacia un tipo de individualismo empresarial planteado por los misioneros, alimenta una conversión más enfocada hacia una «idea de comunidad» (Vilaça, 2002: 69) que valora la autonomía personal como capacidad social constitutiva para la colectividad (Overing, 2003: 299-300).

Bajo esta perspectiva, la adhesión al evangelismo por parte de mis anfitriones urarina no asume la forma de una conversión a un sistema ideológico y moral foráneo, sino más bien representa un acercamiento a un grupo organizado y que incorpora y mantiene fuertemente unidos a sus miembros. De la misma manera, el rechazo a todo progreso personal en términos de poder político y económico podría ser interpretado como una forma de superación del individualismo empresarial propuesto por el proyecto evangélico, en favor de la adopción de una serie de mecanismos que permitirían una mayor valoración de las acciones 
del individuo y de sus capacidades específicas, alimentando así una dinámica relacional que actúa bajo el principio del servicio más que del éxito personal.

En este caso, es el profesor bilingüe que encarna el resultado más evidente de esta lógica. Al revertir las estrategias de evangelización, la figura del profesor transmuta la valoración del bilingüismo, la independencia y el desarrollo personal en herramientas que permiten desempeñar un papel activo en el ámbito político, conformando la función pública a las nociones indígenas de sociabilidad y autonomía, e inmunizando a sus representantes de los efectos dañinos reconocidos a la mayor cercanía con los no indígenas. Tales consideraciones explican el fracaso de los proyectos de impulsar el surgimiento de empresas comunales en la cuenca del Chambira, y como, a raíz de estas tempranas experiencias, el legado misionero ha actuado como precursor de una estrategia urarina de inserción en la vida económica y social nacional.

\section{Referencias citadas}

ALLARD, O., 2012 - Bureaucratic anxiety: Asymmetrical interactions and the role of documents in the Orinoco Delta, Venezuela. HAU: Journal of Ethnographic Theory, 2 (2): 234-256.

BARROS, M. C. D. M., 2004 - A missão Summer Institute of Linguistics e o indigenismo latino-americano: história de uma aliança (décadas de 1930 a 1970). Revista de Antropologia, 47 (1): 45-85.

BELAUNDE, L. E., 2006 - The Strength of Thoughts, the Stench of Blood: Amazonian Hematology and Gender. Tipití: Journal of the Society for the Anthropology of Lowland South America, 4 (1-2): 129-152.

CABRERA, G., 2013 - Apuntes para una historia de los protestantes y su actuación entre los pueblos makú del alto río Negro-Vaupés. In: Upper Rio Negro: Cultural and Linguistic Interaction in Northwestern Amazonia (P. Epps \& K. Stenzel, eds.): 509567; Río de Janeiro: Museu do Índio Funai, Museu Nacional.

CALAVIA SÁEZ, O., 1999 - Os 'homens sem Deus' e o cristianismo: para um estudo dos fracassos missionários. Religião e sociedade, 20 (2): 39-53.

CÓRDOBA, L. I., 2012 - Misioneros-Patrones e indígenas-siringueros: El caucho entre los Chacobos del Beni (Siglo XX). Boletín americanista, 65: 85-106.

D'ANGELIS, W., 2004 - O SIL e a redução da língua Kaingang à escrita: um caso de missão por tradução. In: Transformando os Deuses v. II. Igrejas Evangélicas, Pentecostais e Neo-Pentecostais entre os povos indígenas no Brasil (R. Wright, ed.): 199-217; Campinas: Editora da Unicamp.

DEAN, B., 1999 - Intercambios ambivalentes en la Amazonía: formación discursiva y la violencia del patronazgo. Anthropologica, 17 (17): 85-115.

DEAN, B., 2009 - Urarina Society, Cosmology, and History in Peruvian Amazonia, 344 pp.; Gainesville: University Press of Florida.

DYE, T. W., 1979 - The Bible translation strategy: an analysis of its spiritual impact, Papua New Guinea, 332 pp.; Dallas: SIL. 
ELKINS, R. E., 1993 - Blood sacrifice and the dynamics of supernatural power among the Manobo of Mindanao: Some missiological implications. Missiology, 21 (3): 321 331.

FABIANO, E., 2015a - « Le corps mange, tout comme la pensée soigne » : construction des corps et techniques de contamination dans la pratique chamanique Urarina ; París : École des Hautes Études en Sciences Sociales-EHESS. Tesis de doctorado.

FABIANO, E., 2015b - Función terapéutica de los cantos urarina. In: Descubriendo nuestras identidades. I congreso latinoamericano de etnopsicología: 137-150; Ayacucho: Fondo editorial de Universidad de Ayacucho Federico Froebel.

FRESTON, P., 2004 - Evangelicals and Politics in Asia, Africa and Latin America, 360 pp.; Cambridge: Cambridge University Press.

GRANERO, F. S. \& BARCLAY REY DE CASTRO, F., 1995 - Órdenes y desórdenes en la selva central: historia y economía de un espacio regional, 365 pp.; Lima: Institut Français d'Études Andines, Instituto de Estudios Peruanos.

HANDMAN, C., 2007 - Speaking to the soul: On native language and authenticity in Papua New Guinea Bible translation. In: Consequences of Contact: Language Ideologies and Sociocultural Transformations in Pacific Societies (M. Makihara \& B. B. Schieffelin, eds.): 166-188; Oxford: Oxford University Press.

HEFNER, R. W. (ed.), 1993 - Conversion to Christianity: Historical and Anthropological Perspectives on a Great Transformation, x + 326 pp.; Berkeley: University of California Press.

HOWARD, C., 2001 - Wrought Identities: The Waiwai Expeditions in Search of the 'Unseen Tribes' of Northern Amazonia; Chicago: University of Chicago. Tesis de doctorado.

LALIVE D'ÉPINAY, C., 1975 - El refugio de las masas. Estudio sociológico del protestantisno chileno, 294 pp.; Santiago de Chile: Editorial del Pacífico.

MARTIN, D., 1990 - Tongues of Fire. The Explosion of Protestantism in Latin America, 352 рp.; Oxford: Basil Black well.

OPAS, M., 2006 - Mutually Exclusive Relationships: Corporeality and Differentiation of Persons in Yine (Piro) Social Cosmos. Tipití: Journal of the Society for the Anthropology of Lowland South America, 3 (2): 111-130.

OPAS, M., 2014 - Ambigüedad epistemológica y moral en el cosmos social de los yine. Anthropologica, 32 (32): 167-189.

OPAS, M., 2016 - Dreaming faith into being: Indigenous Evangelicals and co-acted experiences of the divine. Temenos, 52 (2): 239-260.

OVERING, J., 2003 - In praise of the everyday: Trust and the art of social living in an Amazonian community. Ethnos. Journal of Anthropology Museum of Ethnography, 68 (3): 293-316.

RAFAEL, V. L., 2015 - Betraying Empire: Translation and the ideology of conquest. Translation Studies, 8 (1): 82-93.

ROBBINS, J., 2004 - Becoming Sinners: Christianity and Moral Torment in a Papua New Guinea Society, 410 pp.; Berkeley: University of California Press.

TAYLOR, A. C., 1981 - God-wealth: the Achuar and the missions. In: Cultural transformations and ethnicity in modern Ecuador (N. E. Whitten, ed.): 647-676; Urbana: University of Illinois Press.

VIETTA, K., 2003 - Pastor dá conselho bom: missões evangélicas e igrejas neopentecostais entre os Kaiowá e os Guarani em Mato Grosso do Sul. Tellus, 3 (4): 109-135.

VILAÇA, A., 2002 - Missions et conversions chez les Wari'. Entre protestantisme et catholicisme. L'Homme, 164: 57-80. 
Legado misionero entre los urarina de la cuenca del río Chambira (Amazonía peruana)

VILAÇA, A., 2015 - Dividualism and individualism in indigenous Christianity: A debate seen from Amazonia. HAU: Journal of Ethnographic Theory, 5 (1): 197-225.

WALKER, H., 2012 - Demonic trade: debt, materiality, and agency in Amazonia. Journal of the Royal Anthropological Institute, 18 (1): 140-159.

WALKER, H., 2013 - Wild things: Manufacturing Desire in the Urarina Moral Economy. The Journal of Latin American and Caribbean Anthropology, 18 (1): 51-66.

WALKER, H., 2016 - Documents as Displaced Voice: Writing among Amazonian Urarina. The Journal of Latin American and Caribbean Anthropology, 21 (3): 414-433.

WIIK, F. B., 2004 - O evangelho transformado: apropriações Xokleng (Jê) do cristianismo pentecostal. In: Transformando os deuses, vol. II: Igrejas evangélicas, pentecostais e neopentecostais entre os povos indígenas no Brasil (R. M. Wright, ed.): 141-168; Campinas: Editora da Unicamp. 